\title{
Complications of Laproscopic Cholecystectomy in Patients of Acute Cholecystitis
}

\author{
HASEENA REHMAN ${ }^{1}$, GUL LALLEY ${ }^{2}$, GULSHARIF ${ }^{3}$, ASIM SHAFI $^{4}$, ASIF MEHMOOD ${ }^{5}$, MOHAMMAD SHOAIB KHAN ${ }^{6}$ \\ ${ }^{1}$ Medical Officer General Surgery, Muhammad Teaching Hospital, Peshawar \\ ${ }^{2}$ Medical Officer General Surgery, Mian Rashid Hussain Shaheed Memorial hospital, Nowshehra. \\ ${ }^{3}$ Assistant Professor, General Surgery, MTI Lady Reading hospital, Peshawar \\ ${ }^{4}$ Associate Professor General Surgery, Bakhtawar Amin Medical \& Dental College, Multan. \\ ${ }^{5}$ Assistant Professor, General Surgery, Khalifa Gul Nawaz Teaching Hospital, Bannu \\ ${ }^{6}$ Assistant Professor General Surgery Khalifa Gul Nawaz Medical Teaching Institute, Bannu \\ Corresponding Author: Dr Gulsharif, Email: gulafridi1@yahoo.com, Cell No: +92 3005959004
}

\begin{abstract}
Objective: To determine the complications of laparoscopic cholecystectomy in patients of acute cholecystitis. Study Design: Prospective study.

Place \& Duration: Department of Surgery, Lady Reading Hospital, Peshawar for duration of six months from January 2020 to June 2020.

Methods: Total 120 patients of both genders with ages 20 to 60 years were included in this study. Patients' detailed demographics were recorded after taking written consent. Patients with history of abdominal surgery were excluded. All the patients underwent laparoscopic cholecystectomy for gall bladder diseases. Post-operative pain was analyzed by VAS. Complications were recorded at $5^{\text {th }}$ postoperative day. Data was analyzed by SPSS 24.0.

Results: Out of 120 patients 30 (25\%) patients were males and $75 \%$ patients were females. Most of the patients $50(41.67 \%)$ were in the age group 31 to 40 years followed by $37(30.83 \%)$ patients were ages between 41 to 50 years. $70(58.33 \%)$ patients had surgical size port incision was $5 \mathrm{~mm}$ and $50(41.67 \%)$ patients had $10 \mathrm{~mm}$. Mean pain score was $2.24 \pm 1.1$ at $5^{\text {th }}$ postoperative day. Wound infection was found in $10(8.33 \%)$. Port site hernia was found in $12(10 \%)$.

Conclusion: Laparoscopic cholecystectomy is safe and effective treatment procedure with no major complications.

Keywords: Laparoscopic Cholecystectomy, Acute Cholecystitis, Wound Infection, Port Site Hernia, Pain
\end{abstract}

\section{INTRODUCTION}

In the present day, the standard treatment for symptomatic gallbladder stones is a laparoscopic cholecystectomy (LC) with four ports. To avoid scarring, the laparoscopic cholecystectomy (MLC) using an umbilical port has been shown to be a minimally invasive technique for managing and treating benign gallbladder disease. With MLC, patients can return to daily activities sooner, feel better, and have less pain after surgery [2-3]. Patients with advanced age, cirrhosis, or medical contraindications to open surgery can now benefit from MLC [4]. MLC is now a more common treatment for cholecystitis and is simple to perform [5-6]. To reduce the risk of complications, careful monitoring at each stage of the procedure, using standardised surgical and medical measures, as well as adequate skills, is required [7]. Inflammation, adhesions of the normal anatomy make it difficult to find the "critical view of safety" (CVS) and locate the cystic duct and cystic artery, increasing the risk of complications [8].

However, there are still chances of bleeding due to inflamed and friable tissues, making bile leakage and difficulty removing spilled stones more common [9]. The risks of performing LC must be weighed against any potential benefits on a subjective basis. ERCP with stenting may be required if the patient's biliary drainage persists [10]. To reduce operating time and post-operative complications, laparoscopic cholecystectomy was found to be the best option by Tamura et al.

The purpose of this research was to look into the risks and complications associated with laparoscopic cholecystectomy and the diameter of the umbilical port.

\section{MATERIALS AND METHODS}

This study was conducted at Department of Surgery, Lady Reading Hospital, Peshawar for duration of six months from January 2020 to June 2020. A total of 120 patients of both genders with ages 20 to 60 years were included in this study. Following written consent, the detailed demographics of the patients, including their age and gender, were recorded. Major abdominal surgeries, jaundice, acute cholecytitis, patients requiring conversion to open surgery, and patients who did not provide written consent were all removed from consideration.

Each patient received laparoscopic cholecystectomy for gall bladder disease, which was performed in all cases. The pain experienced after surgery was measured using a visual analogue scale (VAS). A total of five complications were reported on the fifth postoperative day. The final follow-up was performed three months after the surgery to determine the occurrence of port-site hernia.

Data was analyzed by SPSS 24.0. Mean+SD was applied. Frequencies and percentages were recorded in tabulation form.

\section{RESULTS}

Out of 120 patients 30 (25\%) patients were males and 75\% patients were females. Most of the patients 50 (41.67\%) were in the age group 31 to 40 years followed by 37 $(30.83 \%)$ patients were ages between 41 to 50 years, 20 (16.67\%) patients had ages between 20 to 30 years and 13 (10.83\%) were ages above 50 years. 70 (58.33\%) patients had surgical size port incision was $5 \mathrm{~mm}$ and 50 (41.67\%) patients had $10 \mathrm{~mm}$. (Table 1 ) 
Table No 1. Baseline characteristics of all the patients

\begin{tabular}{|c|c|c|}
\hline Characteristics & Frequency No. & Percentage \\
\hline \multicolumn{3}{|l|}{ Sex } \\
\hline Male & 30 & 25 \\
\hline Female & 90 & 75 \\
\hline \multicolumn{3}{|l|}{ Age } \\
\hline 20 to $30 \mathrm{yrs}$ & 20 & 16.67 \\
\hline 31 to $40 \mathrm{yrs}$ & 50 & 41.67 \\
\hline 41 to $50 \mathrm{yrs}$ & 37 & 30.83 \\
\hline Above 50 yrs & 13 & 10.83 \\
\hline \multicolumn{3}{|c|}{ Umbilical port site diameter } \\
\hline $5 \mathrm{~mm}$ & 70 & 58.33 \\
\hline $10 \mathrm{~mm}$ & 50 & 41.67 \\
\hline
\end{tabular}

Mean pain score was $2.24 \pm 1.1$ at $5^{\text {th }}$ postoperative day. Wound infection was found in 10 (8.33\%). (Table 2)

Table No 2. Pain score and wound infection according to umbilical port site diameter

\begin{tabular}{|l|l|l|}
\hline Variables & Frequency No. & P-value \\
\hline Mean Pain score & $2.24 \pm 1.1$ & - \\
\hline Wound infection & 10 & 8.33 \\
\hline Yes & 110 & 91.67 \\
\hline No &
\end{tabular}

Port site hernia was found in 12 (10\%) while 108 (90\%) patients had not developed at final follow up.

Figure No 1. Frequency of port site hernia at final follow up

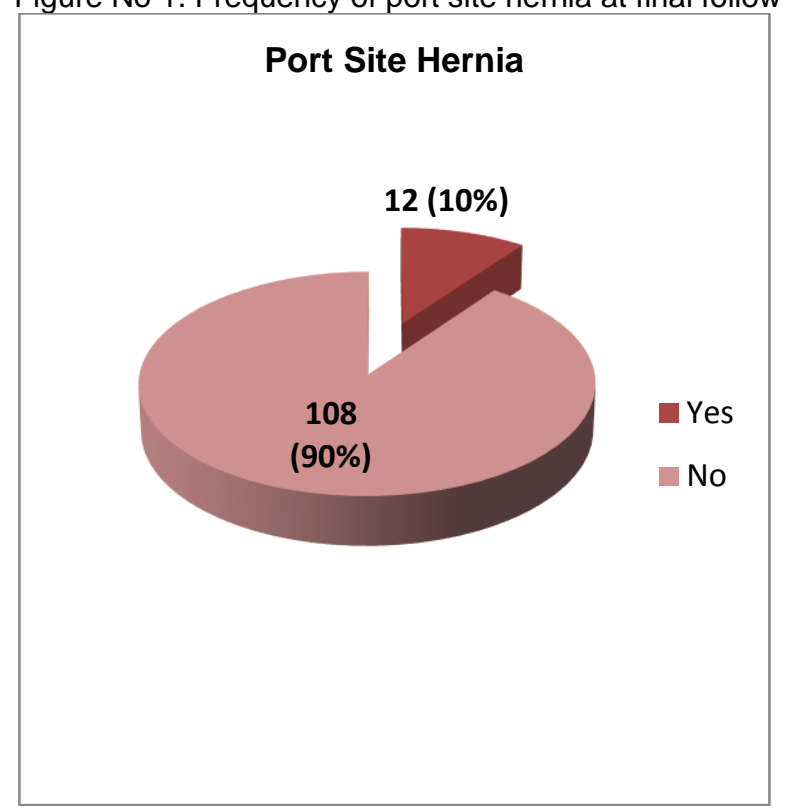

\section{DISCUSSION}

Gall bladder disease and many other abdominal disorders are treated surgically, and laparoscopic operations are becoming popular as a result [12-13]. For gall bladder illnesses, laparoscopic cholecystectomy has been found to be a safe and effective therapeutic option with a low incidence of side effects [14]. For patients with gall bladder problems, many studies have shown that laparoscopic cholecystectomy is the best technique available [15]. To better understand the risks of umbilical port site diameter issues in patients following laparoscopic cholecystectomy, researchers undertook this study. There were 120 patients in our study who underwent laparoscopic cholecystectomy, with 75 percent being female and 25 percent being male. The majority of patients (50/41.67\%) were between the ages of 31 and 40 , followed by $37(30.83 \%)$ patients who were between the ages of 41 and 50, $20(16.67 \%)$ patients who were between the ages of 20 and 30 years, and 13 $(10.18 \%)$ patients who were beyond the age of 50 years. Similar to other research [16-17], the data showed that female patients accounted for 70 to 88 percent of all patients, whereas male patients were primarily aged 35 to 60.

At the fifth postoperative day, we found a pain score of $2.24 \pm 1.1$ in our research. In 10 of the patients, wound infection was found in ( $8.33 \%)$. In a study by $\mathrm{F}$ Usmani et al [18], the mean pain score was found to be $4.7 \pm 2.62$ following laparoscopic cholecystectomy. Postoperative wound infection rates vary from 5 to 20 percent in other studies [19-20]. These findings are consistent.

In this investigation, Twelve (10\%) patients had a hernia at the port site, but $108(90 \%)$ had none by the time of the last checkup. According to these findings, individuals who underwent major surgery and had incisions larger than $5 \mathrm{~mm}$ were at an increased risk of developing a hernia at the surgical site [21-22].

Compared to an open cholecystectomy, laparoscopic cholecystectomy causes less postoperative pain, necessitates less postoperative analgesics, requires less time in the hospital, and allows patients to return to normal activity in one week [23]. Also, compared to open cholecystectomy, laparoscopic cholecystectomy improves cosmesis and patient satisfaction.

\section{CONCLUSION}

In recent years, laparoscopic cholecystectomy has become a widely used surgical procedure because of its effectiveness and safety. We came to the conclusion that laparoscopic cholecystectomy is a safe and effective therapy method with no significant side effects or risks.

\section{REFERENCES}

1. Su WL, Huang JW, Wang SN, Lee KT. Comparison study of clinical outcomes between single-site robotic cholecystectomy and single incision laparoscopic cholecystectomy. Asian journal of surgery. 2016 May 14;(40):424-428

2. Segal DM. Case Report: Modifi ed Laparoscopic Subtotal Cholecystectomy: An Alternative Approach to the "Diffi cult Gallbladder". Am J Case Rep. 2017;18:186-9.

3. Kwon YJ, Ahn BK, Park HK, Lee KS, Lee KG. What is the optimal time for laparoscopic cholecystectomy in gallbladder empyema?. Surgical endoscopy. 2013 Oct 1;27(10):377680.

4. McGillicuddy JW, Villar JJ, Rohan VS, Bazaz S, Taber DJ, Pilch NA, et al. Is cirrhosis a contraindication to laparoscopic cholecystectomy?. Th e American Surgeon. 2015 Jan 1;81(1):52- 5 .

5. Arya SV, Das A, Singh S, Kalwaniya DS, Sharma A, Th ukral BB. Technical diffi culties and its remedies in laparoscopic cholecystectomy in situs inversustotalis: A rare case report. International journal of surgery case reports. 2013 Dec 31;4(8):727- 30.

6. Phothong N, Akaraviputh T, Chinswangwatanakul V, Trakarnsanga A. Simplifi ed technique of laparoscopic cholecystectomy in a patient with situs inversus: a case report and review of techniques. BMC Surgery. 2015;1(15):1-4. 
7. Halbert C, Pagkratis S, Yang J, Meng Z, Altieri MS, Parikh P, et al. Beyond the learning curve: incidence of bile duct injuries following laparoscopic cholecystectomy normalize to open in the modern era. Surgical endoscopy. 2016 Jun 1;30(6):2239- 43.

8. Strasberg SM, Brunt LM. Rationale and use of the critical view of safety in laparoscopic cholecystectomy. Journal of the American College of Surgeons. 2010 Jul 1;211(1):132-8.

9. Akhtar NN, Fawad A, Allam KM. Early Versus Delayed Laparoscopic Cholecystectomy in Acute Cholecystits. PAKISTAN JOURNAL OF MEDICAL \& HEALTH SCIENCES. 2016 Jul 1;10(3):1039-43.

10. Kim KH, Kim TN: Endoscopic management of bile leakage after cholecystectomy: a single-center experience for 12 years. ClinEndosc, 2014; 47(3): 248-53.

11. Tamura A, Ishii $\mathrm{J}$, Katagiri $\mathrm{T}$ et al: Eff ectiveness of laparoscopic subtotal cholecystectomy: Preoperative and long-term postoperative results. Hepatogastroenterology, 2013; 60(126): 1280-83.

12. Kumar S, Tiwary SK, Agarwal N, Prasanna GV, Khanna R, Khanna AK. Predictive factors for diffi cult surgery in laparoscopic cholecystectomy for chronic cholecystitis. Th e Internet Journal of Surgery 2008 : 16 (2).

13. Diamond T, Mole DJ. Anatomical orientation and cross checking-the key to safer cholecystectomy. $\mathrm{Br} J$ Surg 2005;92:63-4.

14. Taha M, Sallam AN, Zakaria HM, Nassar A. Modified technique for two ports laparoscopic cholecystectomy: combined safety and economic value. Egypt J Surg 2019;38:511-6.

15. Leow V, Faizah M, Sharifudin S, Pillai L, Yang K, Manisekar S. Two-incision three-port laparoscopic cholecystectomy. a feasible and safe technique. Med J Malaysia 2014; 69:129_ 132.

16. Elwan A, Abomera $\mathrm{M}$, Atwa $\mathrm{N}$, Abo Al Makarem $\mathrm{M}$. Comparative study between two-port and four-port laparoscopic cholecystectomy. J Arab Soc Med Res 2013; 8:33-37.

17. Sreenivas S, Ravindra S, Gulshan J, Jainendra K, Vipul K, Jitendra C. Two-port mini laparoscopic cholecystectomy compared to standard four-port laparoscopic cholecystectomy. J Minim Access Surg 2014; 10:190-196.

18. F Usmani, M Wasim, A Sheikh, SM Shafqatullah, A Anwar. Modifi ed laparoscopic cholecystectomy: A prospective study focusing on the complications and association in comparison to umblical port diameter: Pak J Surg 2018; 34(2):120-124.

19. Su WL, Huang JW, Wang SN, Lee KT. Comparison study of clinical outcomes between single-site robotic cholecystectomy and single incision laparoscopic cholecystectomy. Asian journal of surgery. 2017 Nov 1;40(6):424-8

20. Ferzli G, Timoney M, Nazir S, Swedler D, Fingerhut $A$. Importance of the node of Calot in gallbladder neck dissection: an important landmark in the standardized approach to the laparoscopic cholecystectomy. Journal of Laparoendoscopic\& Advanced Surgical Techniques. 2015 Jan 1;25(1):28-32.

21. Lee SH, Jung MJ, Hwang HK, Kang CM, Lee WJ. Th e fi rst experiences of robotic single-site cholecystectomy in Asia: a potential way to expand minimally-invasive single-site surgery?. Yonsei medical journal. 2015 Jan 1;56(1):189-95.

22. Reddy SR, Balamaddaiah G. Predictive factors for conversion of laparoscopic cholecystectomy to open cholecystectomy: a retrospective study. International Surgery Journal. 2016 Dec 8;3(2):817-20.

23. Calland JF, Tanaka K, Foley E, Bovbjerg VE, Markey DW, Blome S, et al. Outpatient laparoscopic cholecystectomy: patient outcomes after implementation of a clinical pathway. Ann Surg. 2001 May. 233(5):704-15.

24. Loozen CS, van Ramshorst B, van Santvoort HC, Boerma D. Acute cholecystitis in elderly patients: A case for early cholecystectomy. J Visc Surg. 2018;155(2):99-103. 